\title{
Suicidal overkill - three case reports
}

${ }^{1}$ Faculty of Medicine, University "Ovidius" of Constanta

${ }^{2}$ Bistrita-Nasaud County Forensic Division

\begin{abstract}
All around the globe suicide is an increasing health problem because of the devastating effects that the loss of lives it leaves behind. There are instances when a suicide attempt is but a warning signal, a kind of cry for help, but in some cases its drastic character excludes any doubt about its annihilative aim. There are such situations in which the individuals opting for suicide try to limit the risk of failing in such act to the minimum. This article presents three suicide cases autopsied at the Bistrita-Nasaud County Forensic Division tht share the fact that they use multiple, converging methods of selfdestruction: the first case is that of an elderly man who, after ingesting a significant amount of thiocarbamide pesticides, hangs himself, the second case is that of a policeman in the rural area who, upon an acute alcohol intoxication, shoots himself six bullets in the stomach with the pistol provided, and the third case is of an unknown male citizen who, after sheltering under a bridge, drinks about $600 \mathrm{ml}$ of petrol, then splashed himself with petrol and sets himself on fire.
\end{abstract}

Keywords: suicide method, overkill, atypical suicide

\section{Codrin Rebeleanu}

Bistrita-Nasaud County Forensic division

Garii Street, No. 11, Bistrita, Romania

email : rebeleanuc@yahoo.com

phone: +40744374899

\section{Introduction}

Suicide is the intentional taking of one's own life, and represents a major public health problem [1]. In Greece, in Antiquity, suicidal was disapproved of to such an extent that the corpse was denied ritual burial, and its right hand was severed and buried separately. Suicide is among the first 10 causes of death, irrespective of the age group of the population taken under study [4]. The average mortality rate in Romania reported in 2012 to WHO was 10,5 per 100,000 people [2]. The suicidal act could be seen as a consequence of stigmatisation, meaning a discrepancy between the real and the desired social identity [3], or a natural consequence of a major psychic disorders of the depressive type or of a psychotic component. Drawing a line which distinguish between suicide attempt that could be understood as a cry for help and the real suicidal gesture is very difficult in many cases. Both the choice of the 'location' [5] as well as the choice of the suicide method are factors indicative of the degree in which the individual in question is determined to finish up the self-annihilating act. There is a range of risk factors associated to suicide: genetic, psychopahtological, intra-familial abuse related factors, socio-economic, and even factors related to some behavioural trend (such as the so- 
called 'emo- generation').

There is a very wide range of suicidal ways and of the survival chances rates that suicidal individuals choose to grant themselves. Some situations (warningsuicide or blackmail-suicide) are on the brim between bluff and real suicidal attempt, they sometimes implying a coded desire of claiming psychological assistance. At the other end of the spectrum, there are individuals who opt for tougher suicide ways, which rules out any possibility of survival, and there are those who use several concurring methods in order to nullify the chance of failure. The latter are those who can be considered to have taken a firmer decision in the final approach, without considering any possibility of a change of mind. There are three such cases that particularly drew our attention.

\section{Case presentation}

The article presents a number of three suicide cases whose ways of realization imply more such mechanisms (or one only, but of a repetitive manner) so as the survival chances to be diminished to the maximum.

\section{Gase report 1:}

In April 2016, the body of a 67-year-old male from the rural area is brought to the mortuary of the Bistrita County Hospital in view to its autopsy. The data resulting from the investigation states that the person in case was a farmer and lived alone, as he was a widower and his offspring was abroad. Investigations did not revealed psychiatric problems that require admission to a specialised establishment, not being taken into evidence by the general practitioner. The body had been accidentally discovered by one of the neighbours in an annex of the house of the deceased. The external exam reveals an atypical hanging furrow, discontinued at the level of the right mastoid. The post-mortem confirms death by mechanical asphyxia following hanging, but the gastric content appears as being liquid, milky coloured and with a strong smell of insecticide. Biological samples are collected - blood, gastric content and urine - in the view of performing a toxicological exam. The criminal investigation division was required to perform a second on site investigation, which led to discovering an empty envelope with Dithane Z 78, a fungicide used in agriculture, that contains Zineb, a product with a thiocarbamic structure, falling with toxicity group IV, substance initially considered to be nonessential to the investigation. The toxicological exam of the gastric content disclosed high concentrations with a thiocarbamic structure. Blood's toxicological exam doesn't reveal the presence of such substance, but an alcohol level of $0.23 \%$, which argues in favour of substance's ingestion shortly prior to death. The toxicological exam of the urine shows an alcohol level of $0.45 \%$, and no presence of thiocarbamic substances. The absence of the toxic substances in the blood argues for a determined and decisive of both suicidal methods and their realisation within a short lapse of time, with hanging not being a variant chosen after intoxication symptoms installation, but being earlier prepared.

\section{Case report 2:}

In January 2014, repeated gunshots in a flat made the neighbours call the emergency number. On site there was found a male body, in dorsal decubitus with semi-flected upper limbs. On the sofa next to the body it was found a 'Carpati' pistol $7.65 \times 17$ cal. On the floor there were found cartridge shells and the clothes had burn and soot traces. The pistol had been discharged. The body was identified as belonging to a local policeman. This had been psychologically evaluated 8 months before, and the exam hadn't 
revealed any major psychic disorders. The external exam of the body highlighted 9 orifice wounds within the thoracoabdominal area. Out of these, 7 disclosed secondary factors signs that certified short-range shooting, and the two others, given the absence of the secondary factors to shooting signs, and their 'everted' character, qualified as projectile damage output. The internal exam revealed orifice plagues at the right ventricle, right lung, liver and stomach levels. The spleen presented a massive intraparenchymal dilaceration with two typed of continuity solutions at the capsule level. The alcohol level was found to be $2.25 \%$.

The case was interpreted after corroborating data with that resulted from the investigation, as being a fire arm suicide, following multiple heart, lung, stomach and spleen shot wounds. The cause of death was external and internal haemorrhage caused by the several shot wounds. The realisation method - 7 successive arm fires performed with the provided pistol, which suggests a firm suicidal decision, lacking existential doubts, of the doer.

\section{Gase report 3:}

In October 2011 fire brigade was alerted regarding a fire taking place at the foot of a concrete bridge located off the locality. After extinguishing the fire, a human body was discovered. On calling the criminal investigation division, the latter appealed the County Forensic Division for an on site examination and performing the post-mortem. The body was located on a concrete platform at the foot of a bridge, in the left lateral position, in the 'box fighter position'. Deceased tegument, pilosity and clothes were carbonised. Around the body there were found two plastic containers of 2 litres each, emptied and intensely smelling petrol. After referring the body to the closest mortuary, it was performed a post-mortem. During the autopsy the gastric content proved to be of approximately $600 \mathrm{ml}$ clear liquid, slightly yellowish, intensely smelling petrol. The toxicological exam disclosed an absence of alcohol in the victim's blood. The identification of the deceased person was of no avail, as there were no such fingerprints in the data base. It was concluded that the death of the male person was violent and followed an flame burns. The investigation data corroborated with the post-mortem conclusions lead to interpreting the case as being self-immolation, preceded by ingestion of a certain amount of petrol.

\section{Conclusions:}

Suicidal act represents an action that cannot be easily understood, as it completely opposes the innate survival instinct. The choice of the suicide realisation method can be directed to inflict a minimum of suffering, or can have as a first and foremost aim the self-annihilation, case in which the author's own suffering is considered as negligible.

The situations in which the protagonist takes supplemental measures of redundant character designed to grant the success of the action indicate a higher degree of focusing on the aim, accompanied by a certain narrowing of the individual awareness.

\section{References:}

1. Salem, A., Dragoteanu, C., Marinescu, M. \& Onicas, C. (2009). Atypical methods of suicide - case reports and literature review. Rom. J Leg Med (3), 199-204.

2. Costea, G., Belis, V., Dermengiu, S., Patru, A., Popa, M. \& Popa-Teodosie, S. (1997). Studiu analitic al cauzelor de deces prin moarte autoprovocata. Rom. J Leg Med. 5(4), 375-383.

3. List of countries by suicide rate. (2016). from https://en.wikipedia.org/wiki/List of countries 
by_suicide_rate

4. Florescu, D., DraghiciGh. \& Surdu G. (2004).

Sinuciderea-epifenomen sau consecinta

stigmatizarii. Buletin de Psihiatrie integrative. 18(4), 115-118.

5. Butoi, T., Iftene, V., Boroi, A. \& Butoi, A. (2000).

Sinuciderea - un paradox. Bucuresti: Editura

Stiintelor Medicale. 